\title{
Frequency of verbal transformations as a function of word-presentation styles
}

\author{
KATHARINE A. SNYDER, RICHARD S. CALEF, and MICHAEL C. CHOBAN \\ West Virginia Wesleyan College, Buckhannon, West Virginia \\ and \\ E. SCOTT GELLER \\ Virginia Polytechnic Institute and State University, Blacksberg, Virginia
}

\begin{abstract}
The "arousal" hypothesis was studied by investigating whether a familiar presentation style (a word spoken relatively "normally") would result in more verbal transformations (VTs) than would an unfamiliar presentation style (a word spoken slowly). A VT is any perceptual change that subjects hear when the same word is repeated several times. Forty-three students in an introductory psychology class listened to six neutral words (bedroom, telephone, door, people, subjects, television) repeated for $6 \mathrm{~min}$ with approximately $3 \mathrm{sec}$ between each word. Subjects produced significantly more VTs when the word was spoken normally (familiar) as opposed to slowly (unfamiliar). In addition, the sequence of the presentation styles had no effect. The results are explained in terms of arousal, habituation, word clarity, and attention.
\end{abstract}

To repeat a set of nonsense syllables continuously, Skinner (1936; see Warren, 1968) used an apparatus he called "the verbal summator." He discovered that despite the fact that verbal reports did not match the actual stimulus, subjects were very confident with regard to the accuracy of the sentences and the words they reported hearing. If he had continued the recording, however, Skinner would probably have discovered a phenomenon known as verbal transformation (VT). When the same word is repeated several times, subjects often report that they perceive changes in the word; these changes are called verbal transformations.

Researchers have evaluated individuals' descriptions of word distortions after the successive repetition of the same word. The transformations have ranged from perceptions of words that rhyme with the actual stimulus to more extreme phonetic distortions such as synonyms or antonyms (Calef, Calef, Kesecker, \& Burwell, 1974).

Also, more "arousing" stimuli produced fewer verbal transformations than did "nonarousing" stimuli. For example, neutral words resulted in more VTs than did taboo words (Calef et al., 1974), familiar words resulted in more VTs than did less familiar words (Evans \& Kitson, 1967), and increasing word complexity resulted in fewer VTs (Warren, 1968).

Moreover, subjects with higher intelligence quotients (IQs) seemed to show a greater verbal transformation effect (VTE) than did subjects with lower IQs, possibly because neutral words were less arousing for subjects with higher IQs (Calef, Calef, Piper, Wilson, \& Geller, 1977).

Requests for reprints may be directed to R. S. Calef, Box 12, West Virginia Wesleyan College, Buckhannon, WV 26201.
Given that previous data has shown that familiar words (less arousal) lead to more VTs than do unfamiliar words (more arousal; Evans \& Kitson, 1967), the present study tested the arousal hypothesis further by investigating whether a familiar presentation style (less arousal) would lead to more verbal transformations than would an unfamiliar presentation style (more arousal). Familiar versus unfamiliar presentation style was varied by either speaking the word normally ( $0.5 \mathrm{sec}$ for familiar) or slowly (1.5 sec for unfamiliar). We hypothesized that normal presentation speeds would lead to more VTs than would slower presentation speeds, since the normal speeds should be more familiar (i.e., less arousing).

\section{METHOD}

Subjects

Forty-three general psychology students at West Virginia Wesleyan College served as subjects. They received extra credit toward their grades for taking part in the experiment.

\section{Apparatus}

Two portable cassette stereos (Sanyo and Surround Sound), six 90min blank TDK cassette tapes, and a stopwatch were used.

\section{Procedure}

Two master tapes were used in this study. Tape 1 consisted of Normal Words 1 to 3 on Side A and Normal Words 4 to 6 on Side B. Tape 2 consisted of Slow Words 1 to 3 on Side A and Slow Words 4 to 6 on Side B. Each normal word was spoken for approximately $0.5 \mathrm{sec}$, and each slow word was spoken for approximately $1.5 \mathrm{sec}$. Between each word repetition, there was approximately $3 \mathrm{sec}$ of silence. Each word was repeated for a 6-min period with a 10-sec break after the first $3 \mathrm{~min}$. Each word was spoken approximately 75 times throughout the 6-min period, and there was a 3-min break before switching to a new word.

A four-page structured data sheet similar to the one used by Calef et al. (1979) was used. On Page 1 of the data sheet, the following instructions were printed: 
When I switch on the recording, you will hear a word repeated for $6 \mathrm{~min}$ with a $10 \mathrm{~s}$ break in the middle. I want you to listen very carefully and quietly. If you think the word changes, record a check mark after the appropriate numbered trial on your data sheet, even if the change you hear does not resemble a recognizable word. If the word does not change, mark a dash after the appropriate numbered trial. After $3 \mathrm{~min}$ of word repetition, there will be a $10 \mathrm{~s}$ break, which the experimenter will announce. Place a line after the last numbered trial when the experimenter announces the break. When the recording starts again after the break, begin marking your responses from the first numbered trial. For the final $3 \mathrm{~min}$, if you think the word changes, again check the appropriate numbered trial. If you do not hear a change in the word, again mark a dash after the appropriate numbered trial. After each different word, there will be a 3 min break. Repeat the above procedure for all six of the words.

Two words were printed at the top of each page, and beneath the printed words were two numbered columns with $\mathbf{4 0}$ spaces per column for answers. On one set of data sheets, the words were printed in the following order: bedroom, telephone, door, bedroom, telephone, door. On another set of data sheets, the order of the words was as follows: people, subjects, television, people, subjects, television.

When the subjects arrived, they were asked to choose seats in different rows. The data sheets were handed out, and the subjects were told not to write their names on them. After reading the instructions on the first page, the experimenter asked if there were any questions and then started the tapes. The experimenter sat in the back of the room and only moved once to turn the tape over.

All subjects were tested in a large, well-lighted lecture hall. On Monday evening, Subjects 1 to 15 listened to the words bedroom, telephone, and door (Words 1 to 3 ) in two sequential testing periods. For the first testing period in this session, Subjects 1 to 7 listened to these three words spoken normally (i.e., a familiar style) and then the same words spoken slowly (i.e., an unfamiliar style). For the second testing period, Subjects 8 to 15 listened to these three words spoken slowly and then normally. On Wednesday evening, Subjects 16 to 43 listened to the words people, subjects, and television (Words 4,5 , and 6 ). For the first testing period, Subjects 16 to 36 listened to these three words spoken slowly and then the same words spoken normally. For the second testing period, Subjects 37 to 43 listened to these three words spoken normally and then slowly. Each testing period lasted approximately $75 \mathrm{~min}$.

\section{RESULTS}

The total number of verbal transformations per subject was calculated for each condition. Table 1 illustrates the mean number of verbal transformations for normal versus slow presentation style by order of presentation. As depicted in Table 1, when subjects received the slow presentation style, they experienced fewer VTs $(M=35.68)$ than did subjects who received the normal presentation style $(M=57.31)$. Also, the slow-preceding-normal condition showed a higher mean VT $(M=54.81)$ than did the normal-preceding-slow condition $(M=38.18)$. A 2 (order) $\times 2$ (word presentation style) factorial analysis of variance yielded a significant main effect of wordpresentation style $[F(1,41)=8.72, p<.01]$, a non-

Table 1

Mean Numbers of Verbal Transformations as a Function of Presentation Style and Order of Presentation

\begin{tabular}{lrcr}
\hline & \multicolumn{3}{c}{ Presentation Style } \\
\cline { 2 - 4 } Order of Presentation & Normal & Slow & Total \\
\hline Normal preceding slow & 50.07 & 26.29 & 76.36 \\
Slow preceding normal & 64.55 & 45.07 & 109.62 \\
Total & 114.62 & 71.36 & 185.98 \\
\hline
\end{tabular}

significant order $\times$ presentation style interaction $(p>$ $.05)$, and a nonsignificant main effect of order $(p>.05)$.

\section{DISCUSSION}

The results support our hypothesis that words presented slowly should produce fewer VTs compared with words spoken normally (i.e., a familiar presentation style). Findings were such that the average number of VTs when a word was spoken normally was significantly greater than was the average number of VTs when a word was spoken slowly. Also, we found this effect did not change with order (normal preceding slow or normal following slow), and order per se did not have an effect on VTs, even though Table 1 clearly shows this trend.

These findings support the arousal hypothesis and the previous literature that suggested that diversity, variety, or novelty of the stimulus (i.e., taboo, complex, and unfamiliar words or unfamiliar presentation styles of the words) yield fewer VTs (Calef et al., 1974; Evans \& Kitson, 1967; Warren, 1968). Theoretically, the present findings and the results of previous research suggest that "arousability" of the stimulus, varied through diversity, variety, or novelty (i.e., taboo words, unfamiliar words, complex words, or an unfamiliar presentation style), may be analogous to a sensitization process that facilitates "attention" toward the stimulus and maintains the response (accurate perception of the word) and thus influences fewer VTs. Stimuli that are unarousing (i.e., neutral, noncomplex, or familiar, or a familiar presentation style) may trigger a habituation process that inhibits attention toward the stimulus and produces less response (inaccurate perception of the word), resulting in more VTs.

In addition to the arousal hypothesis, there is one other possible explanation of the results. Since the words were spoken relatively quickly during the normal presentation condition, it is also possible that the normal words were more difficult to perceive than were the slow words and thereby led to more VTs. However, it is noteworthy that the "fast" style was the normal style experienced by the subjects.

Thus, before the results of the present study can be considered as indicating a lawful relationship between word-presentation styles and VTs, several other variables need to be investigated. For instance, the present results might not have occurred if taboo or unfamiliar words rather than six neutral words were spoken with different styles. Also, levels of arousal could be more precisely ascertained if physiological measures were taken as the subjects listened to the words. Finally, it is possible that the present findings might vary as a function of the level of arousal. For example, the results of the present study might have been more pronounced if the subjects had been aroused with anxiety-producing instructions at the start of the task.

\section{REFERENCES}

Calef, R. S., Calef, R. A., Kesecker, M. P., \& Burwell, R. (1974). Verbal transformations of "stabilized" taboo and neutral words. Perceptual \& Motor Skills, 38, 177-178.

Calef, R. S., Calef, R. A., Piper, E., Shipley, D. J., Thomas, C. D., \& GELLER, E. S. (1979). Verbal transformation as a function of boredom susceptibility, attention maintenance, and exposure time. Bulletin of the Psychonomic Society, 13, 87-89.

Calef, R. S., Calef, R. A., Piper, E., Wilson, S. A., \& Geller, E. S. (1977). Imagined verbal transformations as a function of age and verbal intelligence. Bulletin of the Psychonomic Society, 10, 109-110.

Evans, C. R., \& KITson, A. (1967). An experimental investigation of the relation between the "familiarity" of a word and the number of changes in its perception which occur with repeated presentation as a "stabilized" auditory image. National Physical Laboratory Auto Report, Whole No. 36.

SKINNER, B. F. (1936). The verbal summator and a method for the study of latent speech. Journal of Psychology, 2, 71-107.

WARREN, R. M. (1968). Verbal transformation effect on auditory transformation mechanisms. Psychological Bulletin, 70, 261-270.

(Manuscript received March 13, 1992.) 